\title{
STRENGTH OF WHEAT AND BARLEY STEMS AND DESIGN OF NEW BEAM/COLUMNS
}

\author{
Gözde Değer ${ }^{1}$, Mehmet Pakdemirli ${ }^{1 *}$, Feyza Candan ${ }^{2}$, Selda Akgün ${ }^{1}$ and Hakan Boyaci ${ }^{1}$ \\ ${ }^{1}$ Department of Mechanical Engineering, Celal Bayar University, 45140, Muradiye, \\ Manisa,Turkey.mpak@bayar.edu.tr \\ ${ }^{2}$ Department of Biology, Celal Bayar University, 45140, Muradiye, Manisa, Turkey
}

\begin{abstract}
In this study, physical and mechanical properties of wheat and barley stems are examined. Transverse sections of the stems are magnified by a microscope and the material structure in the transverse sections are analysed with image processing programs. Geometric properties such as inner, outer radius, stem wall thickness and density variation of the material along the radius are measured and density variations are approximated by a mathematical model. Moment of inertia of the cross-sectional area which plays a vital role in resistance against bending and buckling is calculated approximately. Using the material density variations of the wheat (Triticum sativum L.) stems, new beam/columns are designed. Stress distributions in this new design and conventional designs of equivalent weight are compared using ANSYS program. It is found that stresses are more uniformly distributed in the new design with maximum stresses being lower than the conventional designs.
\end{abstract}

Keywords- Wheat (Triticum sativum L.) Stems, Barley (Hordeum vulgare L.) Stems, Design of Beam/Columns, Strength

\section{INTRODUCTION}

Engineers play a vital role in transferring scientific knowledge to technology. In recent years, with inspirations from natural designs, engineers contributed a lot to the development of technology by mimicking those designs. Biomimetics is a newly developed branch of science dealing with such applications. One of the interesting designs in nature is the stems of wheat and barley. Despite their extra high slenderness, they possess excellent strength features which enable the plant to bear buckling and bending forces. The stem length can be 500 times the base diameter of the plant and despite this high slenderness, extraordinary strength can be achieved.

The aim of this work is to investigate in detail the strength properties of these stems so that new beam/columns with maximum strength and minimum material can be designed. Some of the previous literature relevant to our analysis will be briefly mentioned. Gowin [1] investigated elastic modulus, shear and bending strength of stems by investigating transverse area and its area moment of inertia. Gibson et al. [2] examined high performance of micro structures and concluded that bending resistence of a beam with anisotropic cell structure is better than a solid beam of equivalent weight. Crook and Ennos, [3] studied wind effects on roots and mechanical properties of stems of wheat for supported and unsupported plants. They found that unsupported plants reveal better strength properties.

Niklas [4] investigated the mechanical behaviour of stems subject to twisting and bending and compared the results with the predictions of elastic stability theory. 
Hornsby et al. [5] examined the micro structure, thermal and mechanical properties of flax and wheat straw fibers and found that cotton fibers have better strength properties than the wheat fibers. They suggest using these fibers for additional strength in thermoplastics.

Cleugh et al. [6] studied wind effects on the growth rates and morphology of the crops. Kronbergs [7] determined ultimate tensile, shear strength, modulus of elasticity and shear modulus of wheat stalks experimentally in order to find methods for mechanical conversion with minimum energy conversion. Hirai et al. [8] measured horizontal and vertical reaction forces of rice and wheat stalks under five different loading speeds. They discussed the discrepancies between the analytical and experimental results. Gibson [9] reviewed the mechanics of a wide range of natural cellular materials and designed engineered biomaterials with a cellular structure to replace tissue in the body. Dawson and Gibson [10] investigated cylindrical shells with compliant cores and presented a more comprehensive analysis by extending the linearelastic buckling theory by coupling it with plasticity theory. They performed an optimal design analysis for cylindrical shells with compliant cores.

Apart from some of the above mentioned studies, where the main concern is biology or agricultural applications, main aim in this study is to investigate the mechanical properties and geometry of the transverse area of stems so that the principles can be applied in designing light beam/columns which can withstand higher loads. The transverse areas of wheat and barley stems are processed using an image processing software and material density distributions along the radial direction are plotted. The plots are approximated by a quadratic function. The elasticity modulus of the stems is also determined experimentally. The inner and outer radii, area moment of inertia for the cross section and their variations along the length of the stem are also plotted. Using the approximate density variation function, a new beam/column is designed with cellular structure. The new design is contrasted with the conventional solid and hollow beam designs using ANSYS program. Stress and buckling analysis is performed using the program. Under same loading conditions with bending and axial loads, the stress distributions are more uniform in the new design and the maximum stresses are lower than the others.

\section{MATERIALS AND METHODS}

In the experimental analysis, wheat (Triticum sativum L.) and barley (Hordeum vulgare L.) are used.

\subsection{Determination of physical properties}

30 specimens of newly harvested and undeformed wheat and barley are selected. Both parts of the stem and spikes of the same specimen are given the same number to identify collectively the properties of a single specimen. Spikes are weighted with a precision weight. Internodes are marked to determine the variation of average inner and outer radii along the length of the stem.

Maximum and minimum diameters are measured by a digital compass. Heights of the internodal marked points from the ground are also measured. 


\subsection{Tensile test}

To determine the elasticity modulus of stems, from each nodal region of 4 wheat and 4 barley plant, rectangular cross sectional thin parts are cut. Each internodal region is marked with letters starting from A, A being the nearest region to ground. For tensile tests, Shimadzu Autograph tensile test machine with $1 \mathrm{kN}$ load cell is used. Modulus of elasticity corresponding to each internodal region is measured from the data of the tests.

\subsection{Taking stem transverse sections to preparates}

To investigate the material structure of transverse sections in a microscope, specimens are subjected to a number of processes. A fixation liquid composed of $70 \%$ alcohol is used to determine the material amount. After extracting from the fixative, the specimen is partially dehydrated by immersing in $80 \%, 90 \%, 100 \%$ alcohol and $2: 1$ alcohol xylol, 1:1 alcohol xylol, 1:2 alcohol xylol and xylol for a suitable time interval. After dehydration process, to fill possible gaps formed in the specimens, the gaps are filled with paraffin. After this process, specimens are placed in paraffin blocks. In a microtom, transverse sections of 35-50 microns in thickness are taken. To withdraw the paraffin from the material, the stages containing the transverse sections are heated over a hot plate. Then they are held in xylol, 2:1 xylol alcohol, 1:1 xylol alcohol, 1:2 xylol alcohol, pure alcohol, 90\% alcohol, 80\% alcohol, 70\% alcohol and pure water in the mentioned order for 5 minutes each. The transverse sections are painted by SARTUR reactive. After this, the transverse sections are held in pure water, $70 \%$ alcohol, $80 \%$ alcohol, 90\% alcohol, pure alcohol, 2:1 alcohol xylol, 1:1 alcohol xylol, 2:1 xylol alcohol and xylol for 1-3 seconds. Therefore, the dehydration process is completed. Preparates are transformed to fixed preparates so that they can be re-used again.

\subsection{Microscopic investigation and photographing}

Optical microscope is used in investigating the specimens. A camera is connected to the microscope to transform the images to a computer. Fotographs are taken in the form of 6-7 pieces from the best appearing transverse sections.

\subsection{Inner and outer radius measurements}

The transverse sections are elliptic being almost circular. In the measurements, from a given transverse section, several measurements are taken by Motic Images Plus 2.0 software and average inner and outer radius and wall thickness are calculated. By combining the data from each labeled transverse sections, variations of these parameters along the height are determined.

\subsection{Determination of material density variations}

Investigating the images of the transverse sections, it is found that the light gray parts correspond to the cell and the dark black parts correspond to cell walls. Inner parts of cell are assumed to be empty and the dark parts are materials. The material density variation along the radial direction is determined by Motic Images Plus 2.0 software.

In the density variation measurements, only transverse sections of wheat are used because the wall thicknesses of wheat are larger than the barley cross sections and variations can be determined with better precision. Rectangular areas are selected over 
pieces of the transverse sections and each material density within the region is recorded. A dimensionless wall thickness parameter is defined

$$
t=\frac{r-r_{i}}{r_{0}-r_{i}}
$$

where $r$ is the radial distance from the center, $r_{i}$ and $r_{0}$ are the inner and outer radius respectively. The material density variations are recorded with respect to this dimensionless thickness parameter for universality of results. From the average measured density points (mid points of each rectangular areas) an approximate curve is drawn. An optimum parabolic function is used to approximate the density variations.

\subsection{Area moment of inertia}

Area moment of inertia is effective in resisting to buckling and bending forces. For the calculation of area moment of inertia, the integral

$$
I=\int_{r_{i}}^{r_{d}} r^{2} \rho(r) 2 \pi r d r
$$

is evaluated. The transverse section area is assumed to be circular with average inner and outer radius. $\rho(r)$ is the density variation along the radial direction. The approximate parabolic function is employed in the calculations. Variation of area moment of inertia with height from the ground is given in the figures.

\section{RESULTS AND DISCUSSION}

In this section, first the measurement results of the plants will be given. Then, based on the density variations of the cross section, a new beam/column design will be proposed and tested using ANSYS program. Comparisons of the new design with conventional designs will be made.

\subsection{Measurements}

To determine the static loads of wheat and barleys, spike weights are measured. The average weight of spikes for wheat is $1.45 \mathrm{~g}$ and for barley it is $3.57 \mathrm{~g}$.

Average outer diameter of wheat and barley corresponding to different heights from the gound are given in Figure 1. The average outer diameter increases some amount with the height and then decreases. Under the effect of aerodynamical forces to the spike, the bending moment will be maximum in the region close to the root. It should be expected that the outer diameter be maximum close to the root. As seen from the figure, it is not the case. One explanation is that, in the measurements, the leaves of the plants are removed and the leaves are wrapped more to the stem close to the root and provide additional strength. 


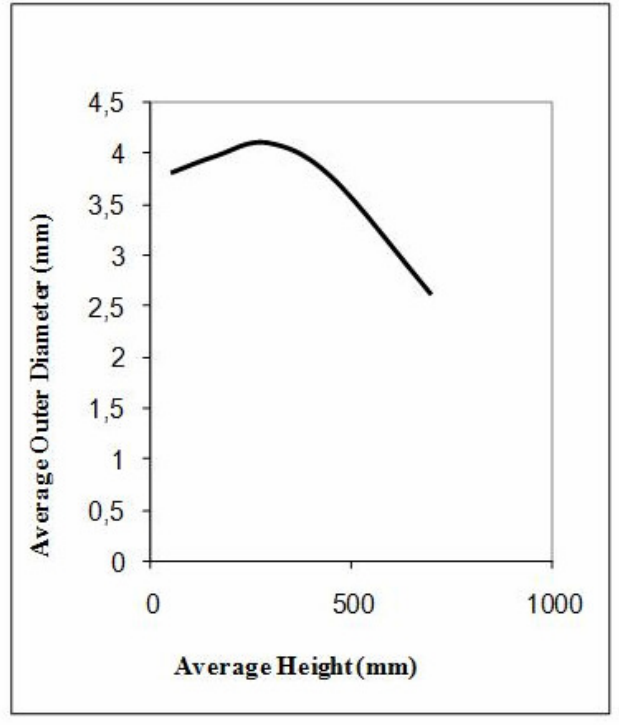

(a)

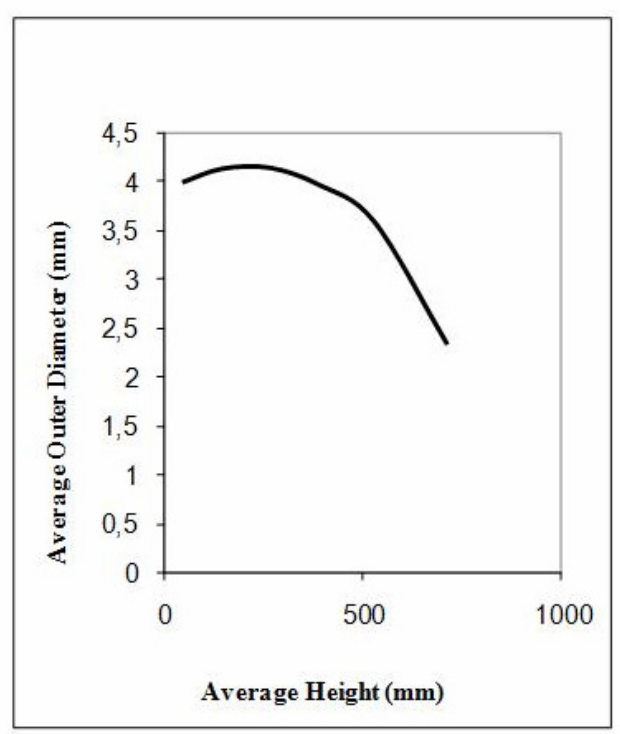

(b)

Figure 1. Average outer diameters vs. average heights for (a) Wheat (Triticum sativum L.) stems (b) Barley (Hordeum vulgare L.) stems

The tensile tests are conducted to determine the elasticity modulus of the specimens. An average value of $6799 \mathrm{MPa}$ is found for wheat stems and $11064 \mathrm{MPa}$ for barley stems. Barley spikes are heavier and therefore the modulus of elasticity to bear higher loads should be greater. Kronbergs [7] reported a higher value of $13100 \mathrm{MPa}$ for wheat stems. Several reasons may cause the discrepancy between the data. First of all, the species are not exactly the same and regional raising conditions have direct effect on the mechanical strength.

In Figure 2, part of a typical transverse section of wheat is shown. Sclerenchyma is the outer tissue which is harder than the inner tissue. Parenchyma is the cellular tissue with larger cells between the inner and outer radius. Since it is of cellular nature, its contribution to strength is less compared to Sclerenchyma. The vascular bundles located nearer to the outer radius contribute much to the strength because they are denser.

The distribution and geometry of the cells are interesting. Cells have hexagonal structure. This structure is found extensively in nature. It is mathematically proven that minimum line length is achieved if a plane is divided into equal hexagonal areas. Minimal line length of course means minimum material. See [2,10] for detailed discussion of hexagonal structures in nature. As a general rule, the cells in the inner parts are larger whereas those in the outer parts are smaller and denser. These plants are subject to high bending moments and to reduce the stresses, the area moment of inertia should be higher. To make the area inertia higher, the cells are located denser near to the outer parts. 


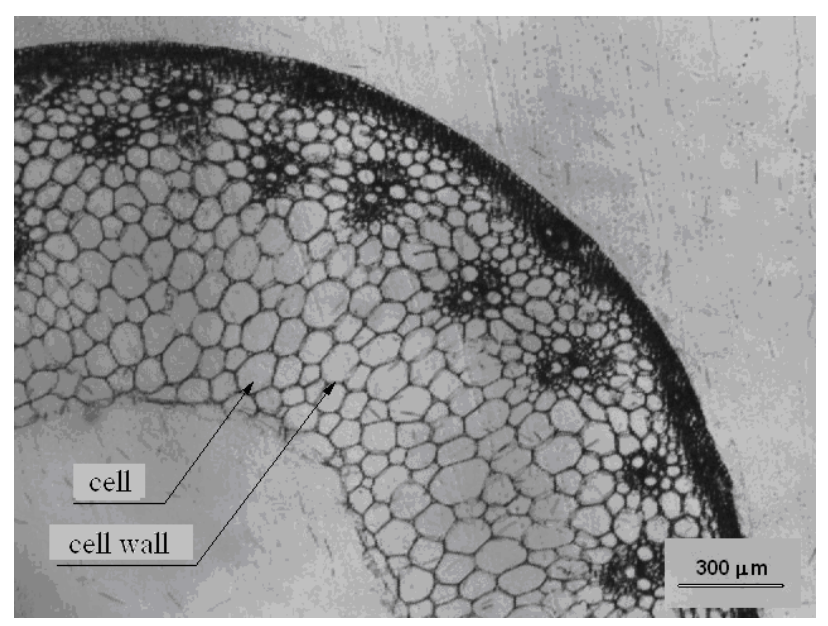

Figure 2. Transverse section of wheat (Triticum sativum L)

In all wheat and barley specimens, inner radius, outer radius and their difference are calculated. Barley diameters are generally higher than the wheat diameters. Reasons for this may be that barley spikes are heavier and barley stems are longer than those of wheat.

In Figure 3, average outer and inner radius values corresponding to height are plotted. Initially, both inner and outer radius values increase a small amount with height and then a sharper decrease is observed. In Figure 4, the average difference between the radii which is the stem wall thickness is presented. The stem wall thickness attains higher values close to the root.

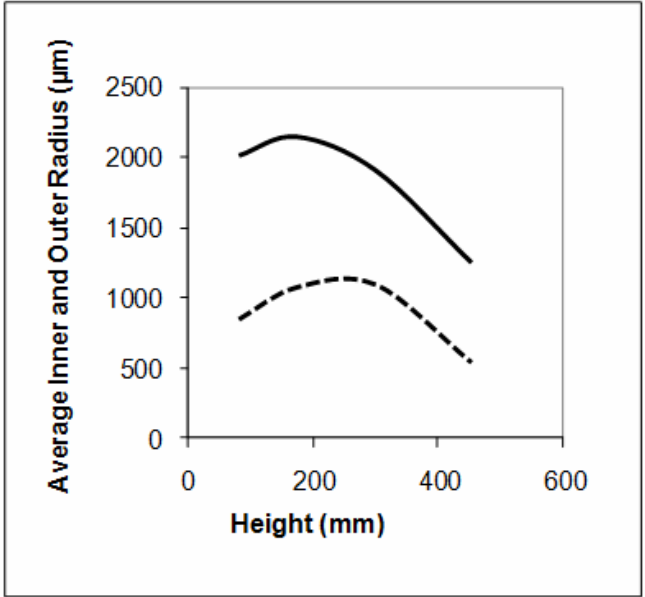

(a)

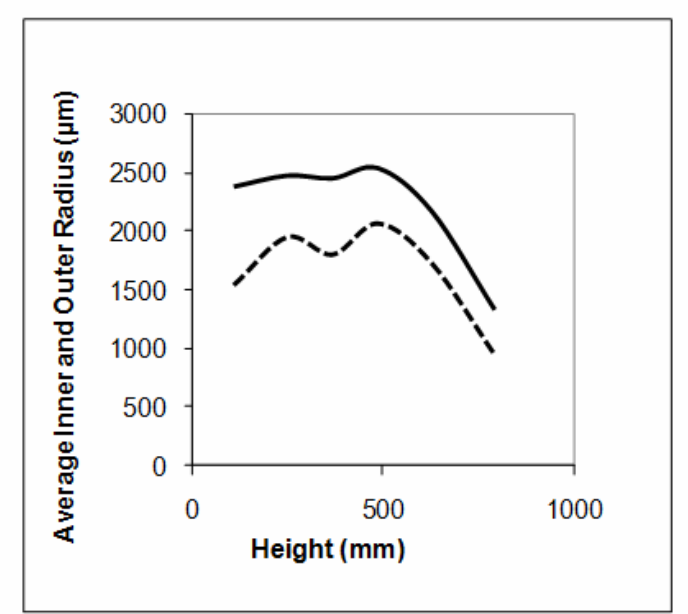

(b)

Figure 3. Outer and inner radii vs. height (a) Wheat (Triticum sativum L.) Stems (b) Barley (Hordeum vulgare L.) Stems (Solid outer radius, dashed inner radius) 


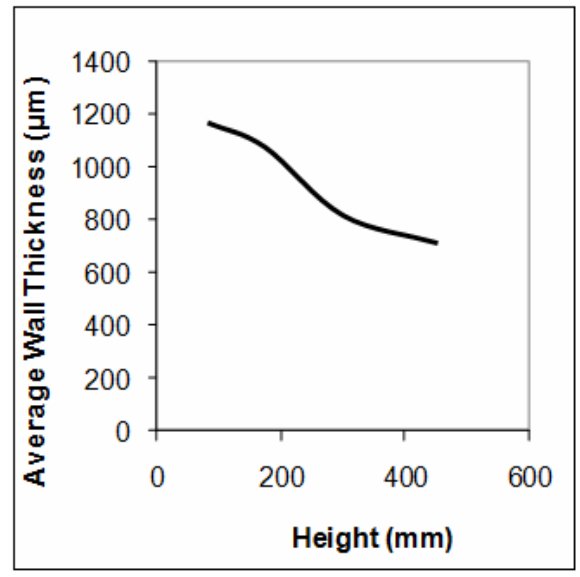

(a)

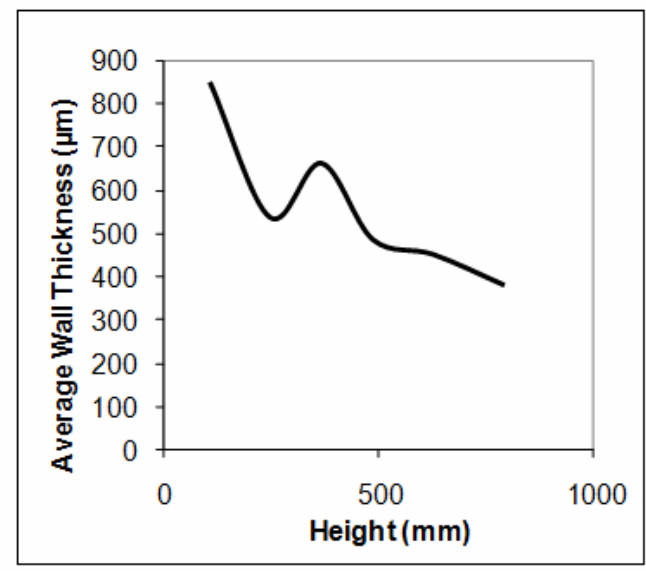

(b)

Figure 4. Stem wall thickness vs. height (a) Wheat (Triticum sativum L.) (b) Barley

(Hordeum vulgare L.)

The material density along the radial direction is presented in Figure 5 for wheat. As pointed earlier, a dimensionless stem wall thickness coordinate defined in equation (1) is used for convenience. An optimum parabolic curve is also drawn as an approximation. Transverse section of internodal point A which is the closest point to the root is used.

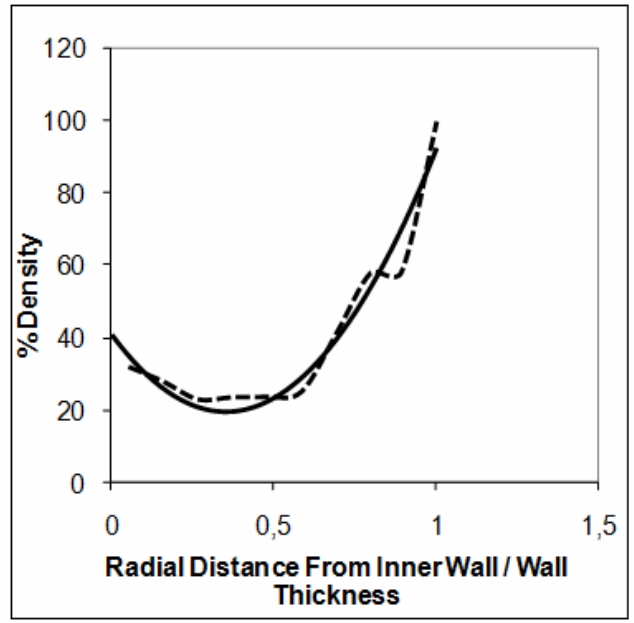

(a)

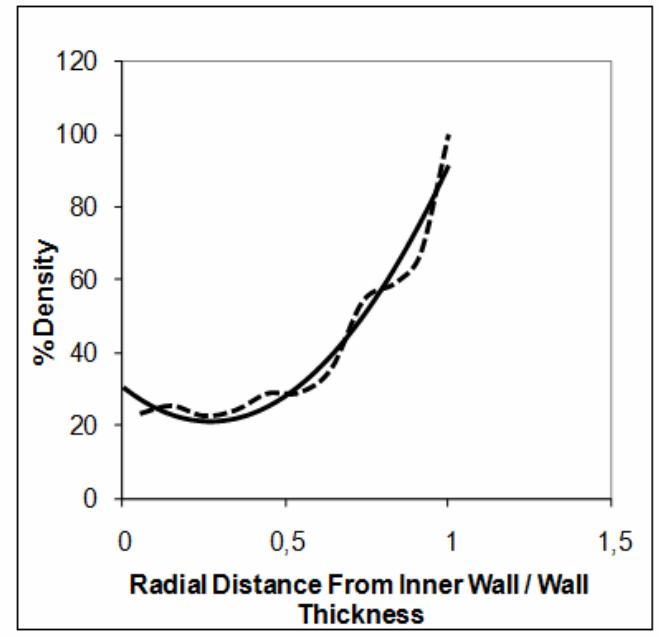

(b)

Figure 5. Density variation vs. dimensionless thickness for wheat (Triticum sativum L.).

Transverse section of internodal point A is used (a) piece \#1 (b) piece \#2 (Dashed measurements, solid parabolic approximation)

Many different specimens are investigated and common features in density variations are observed. Near to the inner radius, there is a small decline observed in density. After a minimal value, density increases sharply attaining $100 \%$ value at the outer radius. The small increase in density in the inner wall may aid in strengthening the stem against local inner wall buckling. 
Using the approximate parabolic distribution, area moment of inertia along the height is also calculated. As height increases, moment of inertia has a peak first and then decreases sharply.

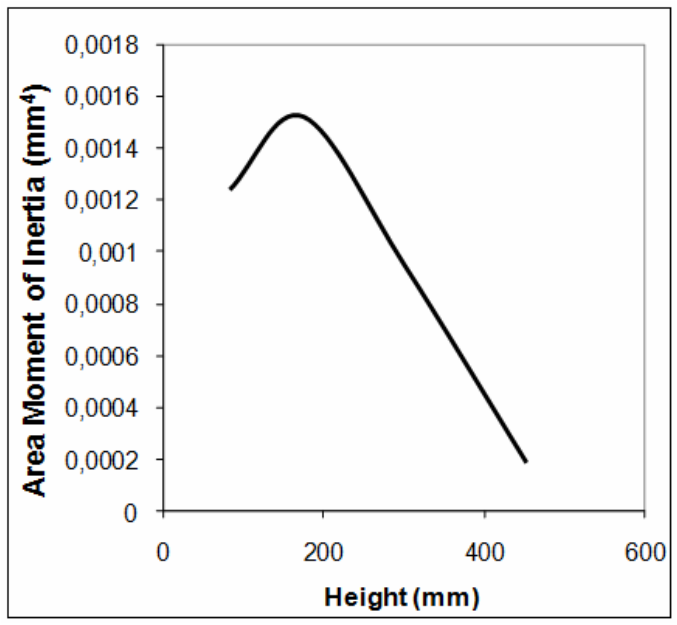

Figure 6. Area moment of inertia vs. height for wheat (Triticum sativum L.)

Bending moments are higher near to the root. To resist bending and buckling forces in this region, the area moment of inertia is designed to be higher. Note that since the leaves wrapped around the stem are removed in the measurements, their additional contribution to strength can not be depicted.

\subsection{Design of new beam/columns}

Using the data of the previous section (i.e. inner, outer radius, density variations) new beam/column design is proposed. The new design mimics the inner and outer radius ratios and density variations of wheat (Transverse section $\mathrm{A}$ ). It has a cellular structure but simplifications in geometry are made so that production can be easier. SolidWorks software is used in the drawings. To compare the efficiency of this design, a solid beam/column and a hollow beam/column with equal outer diameter are also drawn. All beams have the same cross-sectional areas. Geometrical dimensions of the beams are given in Table 1.

In Figure 7, the new beam design is generated based on the geometric properties of piece 1 whereas in Figure 8, geometric propereties of piece 2 is employed.

Table 1. Dimensions of design, solid and hollow beams

\begin{tabular}{|l|l|l|l|l|l|l|}
\hline $\begin{array}{l}\text { Piece \# of } \\
\text { Transverse } \\
\text { Section A }\end{array}$ & $\begin{array}{l}\text { Solid } \\
\text { Beam } \\
\text { Radius } \\
(\mathrm{mm})\end{array}$ & $\begin{array}{l}\text { Hollow } \\
\text { Beam } \\
\text { Inner } \\
\text { Radius } \\
(\mathrm{mm})\end{array}$ & $\begin{array}{l}\text { Hollow } \\
\text { Beam } \\
\text { Outer } \\
\text { Radius } \\
(\mathrm{mm})\end{array}$ & $\begin{array}{l}\text { Desing } \\
\text { Beam } \\
\text { Inner } \\
\text { Radius } \\
(\mathrm{mm})\end{array}$ & $\begin{array}{l}\text { Desing } \\
\text { Beam } \\
\text { Outer } \\
\text { Radius } \\
(\mathrm{mm})\end{array}$ & $\begin{array}{l}\text { Length of } \\
\text { Beam } \\
(\mathrm{mm})\end{array}$ \\
\hline 1 & 144.52 & 178.93 & 230 & 100 & 230 & 1000 \\
\hline 2 & 145.63 & 178.02 & 230 & 100 & 230 & 1000 \\
\hline
\end{tabular}




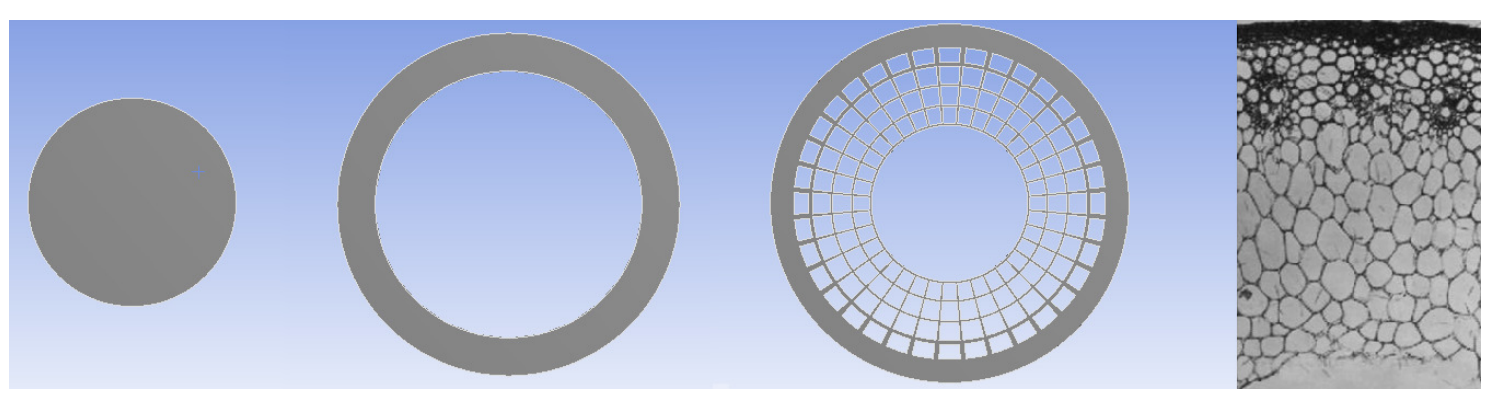

Figure 7- Solid, hollow and design beam cross-sections and image of piece 1 used as a reference in the design.

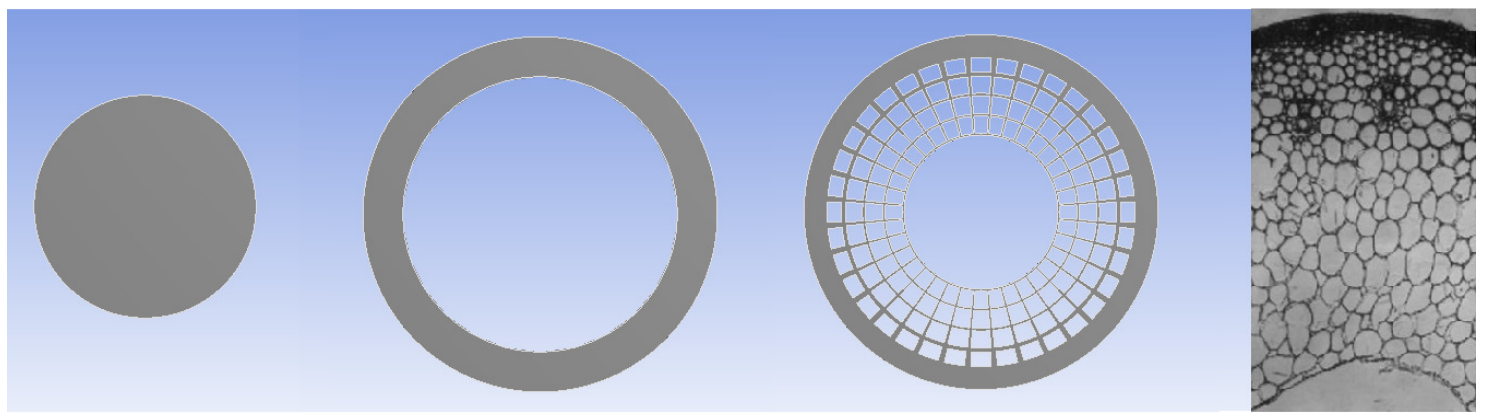

Figure 8- Solid, hollow and design beam cross-sections and image of piece 2 used as a reference in the design.

\subsection{Buckling and stress analysis using ANSYS}

In this section, buckling and stress analysis of solid, hollow and design beam/columns are done using ANSYS. All beams are assigned the same material. One ends of the beams are fixed and the other ends free. Three different loading conditions are tested: i) Axial compressive force of $1000 \mathrm{~N}$ applied to the free end. ii) Shear force of $1000 \mathrm{~N}$ applied to the free end. iii) A combination of both forces. Critical buckling forces, maximum and minimum stress values are determined for all loading conditions. Results for reference piece 1 and piece 2 are given in Tables 2 and 3 respectively.

From Table 2, in all loading conditions, maximum and minimum stresses attain the lowest values in the design beam. This means that stresses are more uniformly distributed in the design beam than the others. Stress concentrations which initiate failure in beams will be lower in the new design. In the case of critical buckling forces, results vary with respect to loading conditions. In the axial and combined loading cases, the design beam has intermediate values whereas in the shear loading, buckling force is the least in the design beam. Note that local wall bucklings are more important in such slender elements compared to global bucklings. Since the local bucklings are associated with stress concentrations, it is expected that the design beam will perform best in wall bucklings.

Similar results can be deducted from Table 3, which is calculated based on the design beam of piece 2 . 
Table 2. Maximum, minimum stresses and critical buckling forces of solid, hollow and design beams (Piece 1)

\begin{tabular}{|c|c|c|c|c|}
\hline Loading & Results & Solid & Hollow & Design \\
\hline \multirow{3}{*}{$\begin{array}{c}\text { Axial } \\
\text { compressive } \\
\text { force of } 1000 \\
\mathbf{N}\end{array}$} & $\begin{array}{c}\text { Equivalent Maximum } \\
\text { Stress (Pa) }\end{array}$ & 20091 & 18299 & 17226 \\
\hline & $\begin{array}{c}\text { Equivalent Minimum } \\
\text { Stress (Pa) }\end{array}$ & 7645.6 & 7207.8 & 5036 \\
\hline & $\begin{array}{c}\text { Critical Buckling } \\
\text { Force (N) }\end{array}$ & $1.6715 \mathrm{e}+8$ & $5.4242 \mathrm{e}+8$ & $5.0856 \mathrm{e}+8$ \\
\hline \multirow{3}{*}{$\begin{array}{c}\text { Shear force } \\
\text { of } 1000 \mathrm{~N}\end{array}$} & $\begin{array}{c}\text { Equivalent Maximum } \\
\text { Stress (Pa) }\end{array}$ & $4.1879 \mathrm{e}+5$ & $1.9951 \mathrm{e} 5$ & $1.8359 \mathrm{e}+5$ \\
\hline & $\begin{array}{c}\text { Equivalent Minimum } \\
\text { Stress (Pa) }\end{array}$ & 4064 & 5023.6 & 1252.5 \\
\hline & $\begin{array}{c}\text { Critical Buckling } \\
\text { Force (N) }\end{array}$ & $2.3268 \mathrm{e}+8$ & $2.8942 \mathrm{e}+8$ & $2.0063 \mathrm{e}+8$ \\
\hline \multirow{3}{*}{$\begin{array}{l}\text { Combined } \\
\text { loading of } \\
\text { axial and } \\
\text { shear forces } \\
\text { of } 1000 \mathrm{~N} \\
\text { each }\end{array}$} & $\begin{array}{c}\text { Equivalent Maximum } \\
\text { Stress (Pa) }\end{array}$ & $4.1952 \mathrm{e}+5$ & $2.1722 \mathrm{e}+5$ & $1.9767 \mathrm{e}+5$ \\
\hline & $\begin{array}{c}\text { Equivalent Minimum } \\
\text { Stress (Pa) }\end{array}$ & 6973.2 & 4549.5 & 2064.4 \\
\hline & $\begin{array}{c}\text { Critical Buckling } \\
\text { Force (N) }\end{array}$ & $1.2427 \mathrm{e}+8$ & $2.547 \mathrm{e}+8$ & $1.941 \mathrm{e}+8$ \\
\hline
\end{tabular}

Table 3. Maximum, minimum stresses and critical buckling forces of solid, hollow and design beams (Piece 2)

\begin{tabular}{|c|c|c|c|c|}
\hline $\begin{array}{l}\text { Loading } \\
\text { Condition }\end{array}$ & Results & Solid & Hollow & Design \\
\hline \multirow{3}{*}{$\begin{array}{c}\text { Axial } \\
\text { compressive } \\
\text { force of } 1000 \\
\mathbf{N}\end{array}$} & $\begin{array}{c}\text { Equivalent Maximum } \\
\text { Stress (Pa) }\end{array}$ & 19810 & 18027 & 17539 \\
\hline & $\begin{array}{c}\text { Equivalent Minimum } \\
\text { Stress (Pa) }\end{array}$ & 7523.3 & 7107.8 & 4937.3 \\
\hline & $\begin{array}{c}\text { Critical Buckling } \\
\text { Force (N) }\end{array}$ & $1.7232 \mathrm{e}+8$ & $5.5069 \mathrm{e}+8$ & $5.1466 e+8$ \\
\hline \multirow{3}{*}{$\begin{array}{l}\text { Shear force } \\
\text { of } 1000 \mathrm{~N}\end{array}$} & $\begin{array}{c}\text { Equivalent Maximum } \\
\text { Stress }(\mathrm{Pa})\end{array}$ & $4.0955 \mathrm{e}+5$ & $1.9676 \mathrm{e}+5$ & $1.8098 \mathrm{e}+5$ \\
\hline & $\begin{array}{c}\text { Equivalent Minimum } \\
\text { Stress (Pa) }\end{array}$ & 3799.2 & 4994.4 & 2119.9 \\
\hline & $\begin{array}{c}\text { Critical Buckling } \\
\text { Force (N) }\end{array}$ & $2.3982 \mathrm{e}+8$ & $2.9941 \mathrm{e}+8$ & $2.0156 \mathrm{e}+8$ \\
\hline \multirow{3}{*}{$\begin{array}{l}\text { Combined } \\
\text { loading of } \\
\text { axial and } \\
\text { shear forces } \\
\text { of } 1000 \mathrm{~N} \\
\text { each }\end{array}$} & $\begin{array}{c}\text { Equivalent Maximum } \\
\text { Stress (Pa) }\end{array}$ & $4.1011 \mathrm{e}+5$ & $2.142 \mathrm{e}+5$ & $1.9563 \mathrm{e}+5$ \\
\hline & $\begin{array}{c}\text { Equivalent Minimum } \\
\text { Stress (Pa) }\end{array}$ & 6640.1 & 4327.7 & 1583.5 \\
\hline & $\begin{array}{c}\text { Critical Buckling } \\
\text { Force (N) }\end{array}$ & $1.3995 \mathrm{e}+8$ & $2.9138 \mathrm{e}+8$ & $1.8744 \mathrm{e}+8$ \\
\hline
\end{tabular}


ANSYS results of stress distributions are given for axial loading (Figure 9), shear loading (Figure 10) and combined loading (Figure 11). As can be seen from the figures, the distributions are more uniform and the maximum stresses are lowest in the design beam.

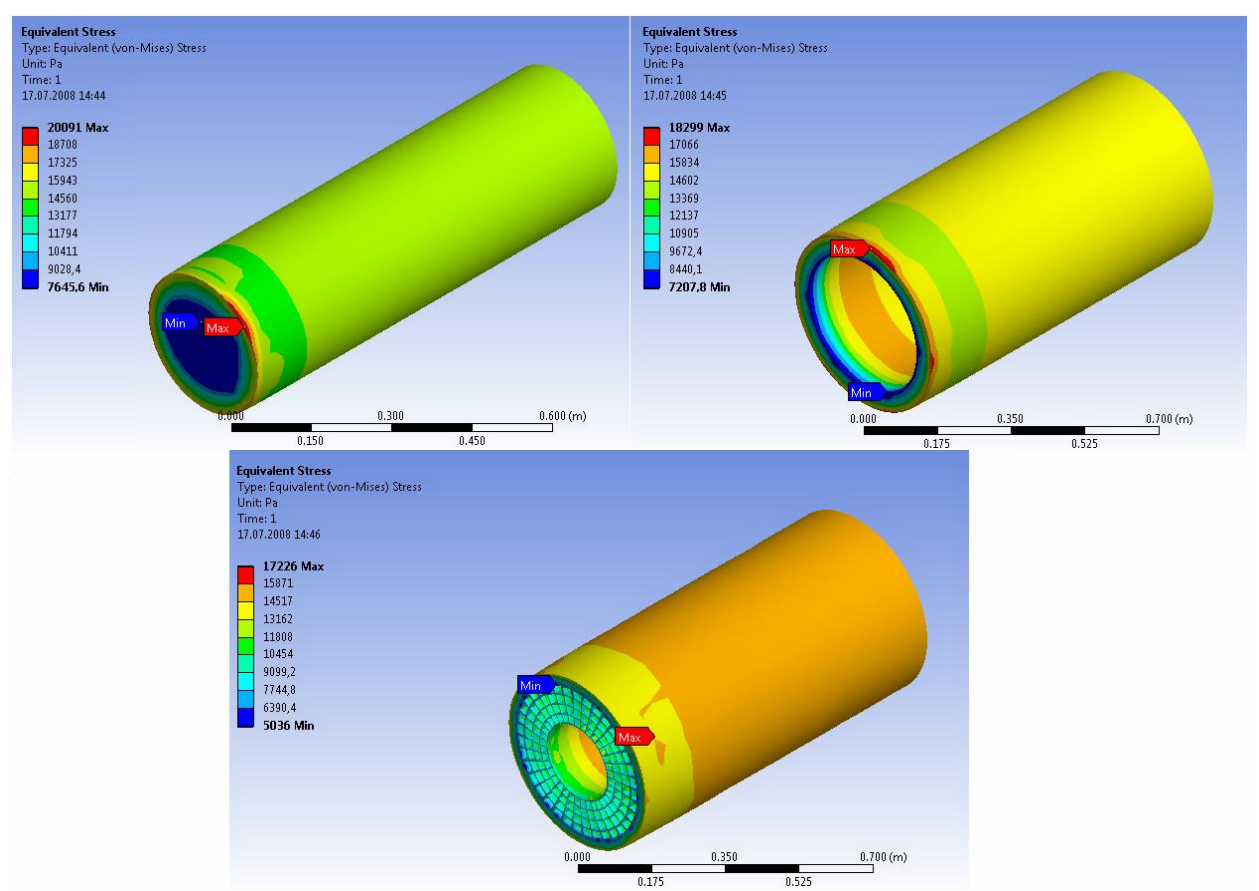

Figure 9- Comparison of stress distributions of solid, hollow and design beams for axial load of $1000 \mathrm{~N}$ with geometric properties taken from piece 1 .

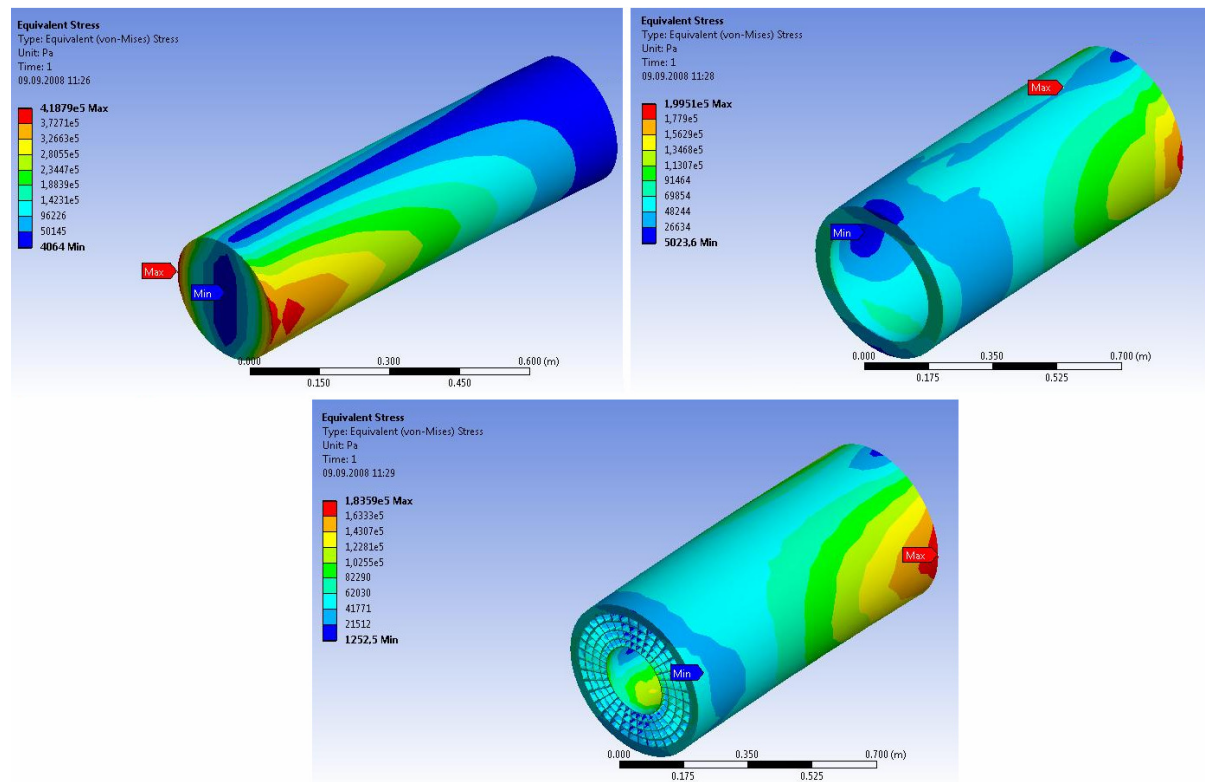

Figure 10- Comparison of stress distributions of solid, hollow and design beams for shear force of $1000 \mathrm{~N}$ with geometric properties taken from piece 1. 


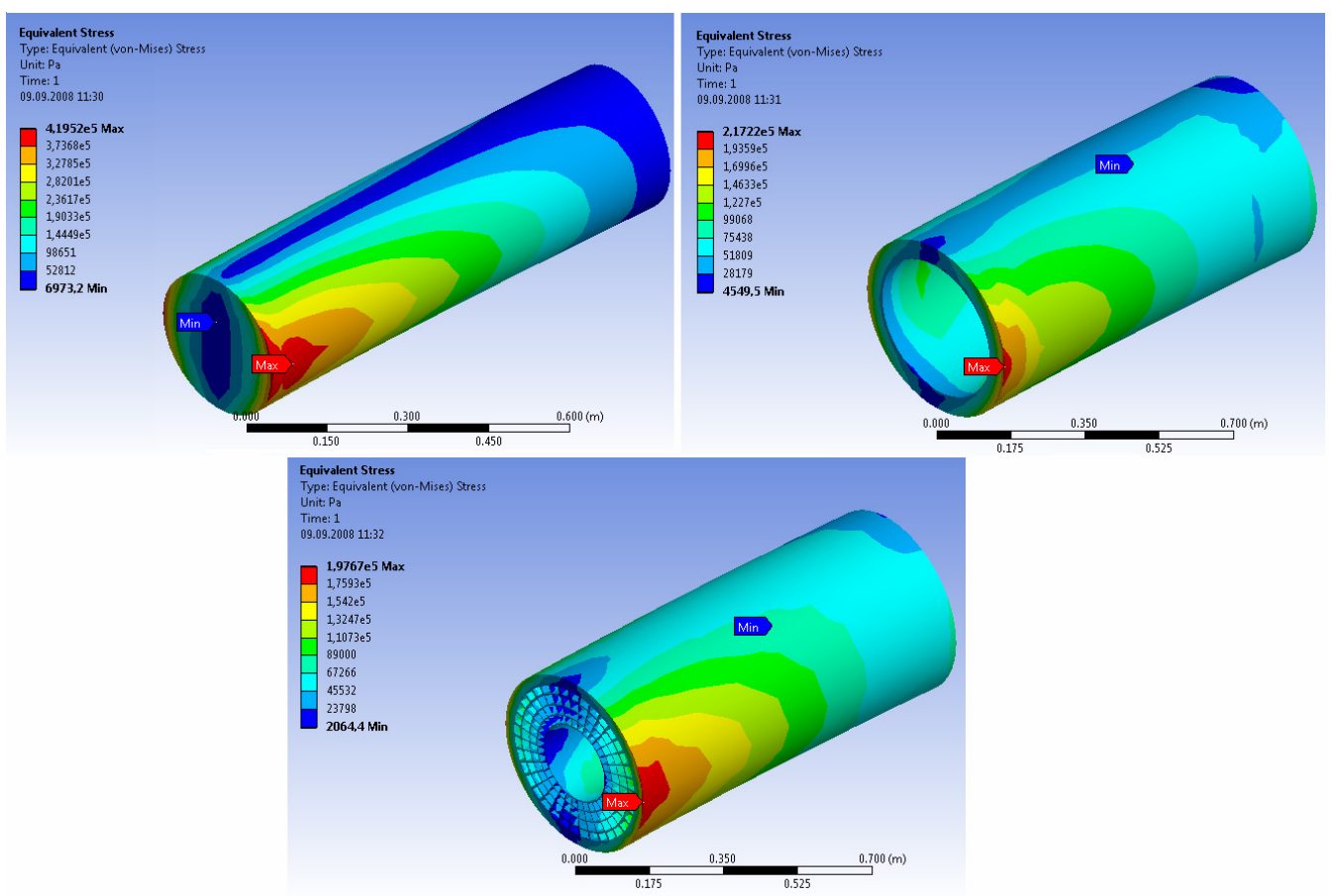

Figure 11- Comparison of stress distributions of solid, hollow and design beams for combined axial and shear load of $1000 \mathrm{~N}$ with geometric properties taken from piece 1 .

Acknowledgment- This work is supported by The Scientific and Technological Research Council of Turkey (TUBITAK) under project number 107T581.

\section{REFERENCES}

1. J. Gowin, Methods for determining geometry of cereal stalk cross-section, 6th International Conference on Agrophysics, Lubnin, Poland, 1977.

2. L. J. Gibson, M. F. Ashby, G. N. Karam, U. Wegst and H. R. Shercliff, The mechanical properties of natural materials. II. Microstructures for mechanical efficiency, Proc. R. Soc. Lond. A 450,141-162, 1995.

3. M. J. Crook and A. R. Ennos, Mechanical differences between free-standing and supported wheat plants, Triticum aestivum L., Annals of Botany 77, 197-202, 1996.

4. K. J. Niklas, Relative resistance of hollow, septate internodes to twisting and bending, Annals of Botany 80, 275-287, 1997.

5. P. R. Hornsby, E. Hinrichsen and K. Tarverdi, Preparation and properties of polyropylene composites reinforces with wheat and flax straw fibres: Part I Fibre characterization, Journal of Materials Science 32, 443-449, 1997.

6. H. A. Cleugh, J. M. Miller and M. Bohm, Direct mechanical effects of wind on crops, Agroforestry Systems 41, 85-112, 1998.

7. E. Kronbergs, Mechanical strength testing of stalk materials and compacting energy evaluation, Industrial Crops and Products 11, 211-216, 2000. 
8. Y. Hirai, E. Inoue and K. Mori, Application of a quasi-static stalk bending analysis to dynamic response of rice and wheat stalks gathered by a combine harvester reel, Biosystems Engineering 88 (3), 281-294, 2004.

9. L. J. Gibson, Biomechanics of cellular solids, Journal of Biomechanics, 38, 377-399, 2005.

10. M. A. Dawson and L. J. Gibson, Optimization of cylindrical shells with compliant cores, International Journal of Solids and Structures 44, 1145-1160, 2007. 